\title{
The Optimal Formula for Organic Oil Immobilization in Algerian Petroleum Drill Cuttings Using Solidification/Stabilisation Treatment
}

\author{
Abbas Hadj Abbas ( $\square$ abbashadjabbas@gmail.com ) \\ Kasdi Merbah Ouargla University: Universite Kasdi Merbah Ouargla \\ Abidi Saad Aissa \\ Kasdi Merbah Ouargla University: Universite Kasdi Merbah Ouargla \\ Khodja Mohamed \\ Universite de Boumerdes: Universite M'Hamed Bougara Boumerdes \\ Sagala Farad \\ University of Calgary \\ Hacini Messaoud \\ Kasdi Merbah Ouargla University: Universite Kasdi Merbah Ouargla
}

Research Article

Keywords: drill cuttings, solidification/stabilization, Portland cement, compressive strength, Total Petroleum Hydrocarbon (TPH)

Posted Date: August 5th, 2021

DOI: https://doi.org/10.21203/rs.3.rs-773441/v1

License: (c) (i) This work is licensed under a Creative Commons Attribution 4.0 International License. Read Full License 


\section{Abstract}

Hassi Messaoud oil field is one of the most important fields in Algeria and the world, because it covers an important quantity of total Crude Oil Production in Algeria. Furthermore, two-thirds of this oil field is underexplored or not explored. Therefore, the drilling process of petroleum wells in this field is a continuous process that results in significant drilling waste. This implies that, enormous noxious quantities of drilling waste are produced daily that require treatment via solidification/stabilization $(\mathrm{S} / \mathrm{S})$ process before being landfilled. These types of wastes have pollution concentration that significantly exceeds the safety standards. In this study, we focus on the factors affecting the solidification/stabilization treatment of the drill cuttings obtained from Hassi Messaoud oil field and the process optimization. The solidification/stabilization is performed using the cement as binder, sand, silicate, organophilic clay and activated carbon as additives.

The study is divided in two steps:

(i) aims to determine the optimum ratio of each element used in the S/S process for the organic element (hydrocarbon) elimination,

(ii) aims to combine the optimum ratios found in the previous step to determine the optimal mixture.

The obtained results in the first step showed that the optimum ratio for the cement-to-drill cuttings mass ratio is $0.09: 1$. For the additives-to-drill cuttings

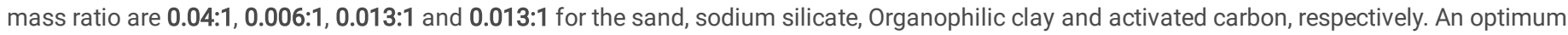
formula is found which its main finding shows that the hydrocarbon content of our sample is dropped from 9.40 to $1.999 \%$. Many tests results before landfilling were investigated such as matrix permeability, resistance to free compression and heavy metals rate before and after S/S process. Besides that, in the light of outcomes achieved by this assessment these harmful cuttings can be converted into a useful product that helps in reducing the environmental foot prints.

\section{Introduction}

Crude oil and natural gas are among the most important energy sources in the world(Yoon et al., 2009). The process of crude oil extraction involves several stages, the most important of which is drilling. Basically, drilling activities result in significant amount of cuttings that present adverse environmental impacts due to the use of certain drilling fluids such as oil-based drilling fluids (Laroche et al., 2016). These drill cuttings consist of various solid particles from the rocks and liquids released from geological formations from the drill hole. Moreover, toxic and carcinogenic elements of heavy metals and hydrocarbon are contained in these cuttings. The source of these harmful elements is the oil-based drilling fluid and their additives. Due to the presence of these dangerous elements, these cuttings cannot be discharged directly into the environment (S et al., 2010). Some techniques were used to treat the drill cuttings before being discharged; such as thermal, chemical, solidification/stabilization and bioremediation treatments (Boutammine et al., 2020). Solidification/Stabilization (S/S) commonly applied to the treatment of cuttings due to its significant effectiveness (S et al., 2010). This Stabilization (or inerting) process involves treating the noxious waste using a hydraulic binder. While solidification process of contaminants necessitates development of a solid mass with sufficient structural integrity to allow transport or storage without using a container(Vehlow, 2012).

Stabilization/solidification and biological process combination study was investigated by Boutamine et al., (Boutammine et al., 2020). They reported that unconfined compressive strength was significantly affected and also the hydrocarbon was reduced. Previously, a mixture of cement, fly ash, lime and calcium oxide has often been used as a S/S additives for treating drill cuttings and some other types of wet solids (Vehlow, 2012). The interactions between a waste and a binder during the S/S technique to develop its effectiveness was investigated by Sunday et al., (Leonard et al., 2010), using Fourier Transform Infrared (FTIR), Scanning Electron Microscopy (SEM) and Differential Scanning Calorimetry (DSC) technics. Comparative study between solidification/stabilization and thermal-treatment methods had been also performed by Kherfi et al., (Kherfi et al., 2018). Their results revealed that the S/S method is more effective for eliminating the concentration of heavy metals and organic materials presented in the Algerian drill cuttings. Leonard et al., (Leonard and Stegemann, 2010) added a high carbon fly ash to the Portland cement, as a novel binder, to improve the leachability-related properties of $\mathrm{S} / \mathrm{S}$ treatment of oil drill cuttings. The results showed that high carbon fly ash improved the immobilization of organic contaminants for S/S of organic drilling wastes. To improve a cement- based solidification/stabilisation of a soil contaminated by nitrobenzene, an orthogonal experiment was applied by Liu et al., (Liu et al., 2012). In their experiment, cement and lime were used as binders; sodium-silicate solution and powder activated carbon were employed as additives. Leaching test and volatilization measurement had been adopted to estimate the efficiency of stabilization/solidification process. Cement based solidification/stabilization for solids wastes treatment has been reported by other researchers elsewhere (Vaccari and Castro, 2019).

Despite the efficiency of the reported treatment techniques in literature, there still a persistent need for more development of these technics that treat the harmful petroleum residues before being landfilled to the environment. Normally, landfilling of treated drill cuttings is the last procedure during their management and disposal to the environment. Therefore, it requires paramount treatment and optimization. Furthermore, it is necessary to reduce or to entirely-neutralize all the hazardous petroleum residues in these drilling wastes in order to protect the environment.

Herein, we aim to optimize some of the parameters used in the solidification/stabilization treatment of the drill cuttings from Hassi Messaoud oil field. This field is one of the most important fields in Algeria and in the world, because it covers an important quantity of total Crude Oil Production in Algeria of high quality (Light crude oil, API = 45) (Larbi et al., 2015). Moreover, apparently, two-thirds of the Algerian territory still mainly underexplored or unexplored. Which implies that there are/will be a huge need for more advanced (solidified/stabilized) treatments to neutralize the drilling wastes before their landfilling for more environmental protection. Because, these types of wastes have pollution concentration that exceeds the safety standards significantly. This study is divided into two main steps: 
(i) Determining the impact of the cement as binder and the commonly used additives such as sodium silicate, activated carbon, organophilic clay and sand during the S/S treatment. Also, finding the optimal required quantity for each parameter for effective treatment during S/S process. (ii) Combining the optimal quantities found in the step one to determine the best combination that gives the highest hydrocarbon toxicity reduction from the drill cuttings.

The results show that the selected parameters significantly improved the S/S disposal technology for hazardous hydrocarbon removal from drill cuttings. In fact, to the authors' knowledge and according to the literature survey, all previous works, which dealt with S/S technic aiming to neutralize the harmful wastes before their landfilling, were made for other oilfields and just the effect of one or two parameters are studied. Accordingly, this is the only work focuses on the optimization of S/S technic by optimizing all important parameters and combining them to extract the best mixture that can make the landfilled cuttings riskiness under the safety standards in Hassi Messaoud oil field which it can be applicable for other fields.

\section{Materials And Methods}

2.1 Materials

2.1.1. Sample isolation and characterization

The samples were taken from different places and depths from the same drilling-wastes quagmire, in order to have a representative sample of drill cuttings. Special attention was taken during the sampling process and each sample was homogenised before any further testing. The obtained samples were characterized to determine the exact continents of hazardous materials such as the heavy metals and the hydrocarbons.

\subsubsection{Additives}

\subsubsection{Sand}

Solid sand was used in the experiences and their Characterization are mentioned in Table 1.

\subsubsection{Sodium silicate}

The sodium silicate (SS) solution was added to each sample of drill cuttings to reduce the hydrocarbon continent and make a better strength of the solidified body.

\subsubsection{Powder Activated Carbon (PAC)}

To improve the efficiency for immobilization of the hydrocarbons in petroleum drill cuttings selected inexpensive thermally regenerated activated carbon has been evaluated.

\subsubsection{Organophilic clay}

The organophilic clay used in this study was prepared according to the same protocol as that mentioned in reference (Montgomery et al., 1991). The used organophilic clay has the capacity to adsorb organic compounds such as oil from drill cuttings.

\subsection{Methods}

2.2.1. Characterization of Ordinary Portland Cement (OPC),The mineralogical, chemical and particle size composition of the used hydraulic binder (ordinary Portland cement, OPC) was determined using X-ray diffraction (XRD), X-ray fluorescence analysis (XF) and analysis by Laser Granulometry respectively according to the following conditions:

\subsubsection{X-ray diffraction (XRD)}

PANalytical diffractometer: XPERT-PRO, ceramic X-ray tube with copper anticathode, RX generator power: 40 mA, 45 kV.

Software for data acquisition: PANalytical Data Collector

Data processing software: High Score Plus from PANalytical.

Wavelength CuKa $[\AA]$ : 1.5418.

Departure angle [2Ө]: 2,0000

Final angle [20]: 70.0000

Step size [20]: 0.0170

Step time [s]: 91.7599

2.2.1.2 X-ray fluorescence analysis (XF) 
The natural sample in powder form is mixed with lithium tetra borate, heated to $1200^{\circ} \mathrm{C}$ in order to obtain a homogeneous transparent glass (borate pearl) which will be used for the analysis of major elements. The pearl obtained is subjected to a source of primary X-rays. It follows an excitation of the atoms that will emit a secondary X-ray fluorescence characteristic of the chemical composition of the sample analyzed. According to an analysis program previously established on international standards by type of sample, the concentration of the chemical elements making up the sample is determined.

Sequential spectrometers (wavelength dispersive) Bruker-Axs: S8 TIGER.

Rhodium anode.

Software for data processing: Spectra plus.

The concentration of an unknown sample is determined by calibration curves which are plotted for each element after fixing all the measurement parameters (kV-mA, crystal analyzer, collimator, emission wavelength, time and the detector).

\subsubsection{Analysis by Granulometry Laser}

The analysis of the samples was carried out using a LA 950 type laser particle sizer. The distribution statistics are calculated from the results, using the derivatives $D[m, n]$ :

$\mathrm{D}(\mathrm{v}, 0.1), \mathrm{D}(\mathrm{v}, 0.5)$ and $\mathrm{D}(\mathrm{v}, 0.9)$ are standard percentile measures of the analysis.

D $(v, 0.5)$ : is the particle size for which $50 \%$ of the sample is smaller and $50 \%$ of the sample is larger than this size and also known as MMD (Mass Median Diameter).

D $(v, 0.1)$ : is the particle size for which $10 \%$ of the sample is below this dimension.

D (v, 0.9): is the particle size for which $90 \%$ of the sample is below this dimension.

The span: is the measure of the width of the distribution, the smaller this value the narrower the distribution. The width is calculated by the following formula:

$$
\text { width }=\frac{\mathrm{D}(0.9)-\mathrm{D}(0.1)}{\mathrm{D}(0.5)}
$$

\subsubsection{Mixing}

Mixing equipment is an electric agitator brand Hamilton Beach. It has a load-bearing axle of a propeller and achieves rotational speeds of 18,000 rpm.

\subsubsection{Oil content in drill cuttings (Hydrocarbon \%)}

The oil levels in drill cuttings were measured using InfraCal 2 Analyzer. It is a compact, fixed-filter, mid-infrared analyzer with no moving parts.

The analysis procedure involves the following simple steps:

The sample is collected in a container.

The solvent hexane is added to tested sample.

After two minutes' shaking the solvent partitions, a portion of which is introduced to the infrared analyzer for measurement; the solids are filtered from the solvent prior to testing.

Taking the final results of oil levels (Hydrocarbon \%).

\subsection{Matrix permeability test}

Nitrogen $\left(\mathrm{N}_{2}\right)$ gas Permeameter was used to determine the permeability of the treated cylindrical sample, under a pressure of 40 bars. Fig 1 shows the schematic consisting of the elements of the Permeameter: (2) the head pressure transducer composed of a pressure sensor and a purge, this part makes it possible to supply the inlet pressure to the sample, (3) the confinement pressure transducer formed also by a purge and a pressure sensor, and (4) the lower pressure transducer fitted with a pressure sensor, a flow meter and a tap to control the outlet pressure of the sample (Rosener, 2008). Inlet and outlet pressures were carried out for gas permeability measurements. The applied head pressure can reach 35 bars. The sample sizes are measured, and the permeability is calculated using the Darcy's law; then, it is corrected of the Klinkenberg's effect (Tanikawa and Shimamoto, 2006).

2.2.5 Resistance to free compression (RFC): 
The resistance to free compression (RFC) test is carried out for cylindrical samples of (diameter $\times$ height): $75 \times 150 \mathrm{~mm}$ (Krauthammer et al., 2003). The molds for the test cylinder are made of polished steel or cast iron to avoid adhesion of the cement sample to the sides. Each mold should rest on an adjusted metal base to prevent leaks. The test samples should be stored at a temperature above $10^{\circ} \mathrm{C}$. It should be noted that the sample is subjected to this test after treatment, since it is brittle before treatment (zero compressive strength). Thereafter, the solidification of our waste intended for landfilling can be assessed easily.

\subsubsection{Atomic absorption spectrophotometry for the retention of heavy metals}

Leaching test allows liquid-solid extraction. After contacting the test sample with an aqueous solution ( $25 \mathrm{~g}$ of the sample in $250 \mathrm{ml}$ of acidified distilled water $(\mathrm{PH}=2,88)$ to simulate acid rain), which allows the passage of soluble heavy metals in the solution. This is followed by a subsequent separation (filtration), allowing the obtaining of one or more eluent. The latter are analyzed by the atomic absorption spectrophotometry (AAS) method, which quantifies the concentrations of heavy metals for the drill cuttings before and after solidification/stabilization process.

\subsubsection{Scanning electron microscopy (SEM)}

Scanning electron microscopy was carried out to study the surface morphology of the treated drill cuttings at different times after mixing (curing time). A Supra 40VP Colonne GEMINI Zeiss scanning electron microscope was used, with an accelerating voltage of $15 \mathrm{kV}$.

\subsubsection{Acceptance tests of the treated waste}

Since the strength test of the treated samples is made for the detection of the samples stabilization. Therefore, after mixing of our samples, the compressive strength is analyzed for several periods: $3,7,21,28$ and 96 days.

\subsubsection{Solid/liquid separation}

Solid / liquid separation is obtained using a centrifuge type Megafuge 2.0, marque Heraeus. It can reach the speed of $3500 \mathrm{rpm}$ for a period of 45 minutes.

\section{Results And Discussion}

3.1 Characterization of crude drill cuttings

\subsubsection{Heavy metals and hydrocarbons content}

From the results shown in Table 2, the harmful elements that exist in the studied crude cuttings are mostly the heavy metals and hydrocarbons. The heavy metals are namely; Lead $(\mathrm{Pb})$, copper

(Cu), chromium ( $\mathrm{Cr}$ ), Cadmium (Cd), Zinc ( $\mathrm{Zn}$ ) and manganese (Mn). As it can be seen from this table, there are some samples that have elements of amounts exceed the maximum tolerated values for hydrocarbons and heavy metals (Khodja, 2008). Thus, the current drill cuttings are conventionally toxic (Lake and Menzies, 2007) and can not be landfilled and hence, further treatments are needed.

\subsection{Characterization of Ordinary Portland Cement (OPC)}

The mineralogical, chemical and particle size composition of cement has an important role in the properties of solidification/stabilization (S/S). Below are some results:

\subsubsection{Mineralogical analysis}

Analysis by X-ray crystallography of the cement sample revealed the mineral phases Hatrurite Ca3SiO5, Brownmillerite Ca2FeAl05 and Gypsum $\mathrm{Ca}(\mathrm{SO} 4)(\mathrm{H} 2 \mathrm{O})_{2}$ (see Fig.2a).

\subsubsection{X-ray fluorescence analysis}

The chemical analysis results of the major elements expressed in percentage by mass (\%) are given in table 3.At the end of these two analyzes we can conclude that the sample is made up of minerals which are part of the constitution of a cement, namely hatrurite and brownmillerite. In addition, the presence of gypsum is noted in very low concentrations, a level of $(\mathrm{CaO})$ at $64.33 \%$, and the presence of sulfur $\left(\mathrm{SO}_{3}\right)$ is also noted at $1.83 \%$.

\subsubsection{Granulometric distribution}

The composition and the grain size of the cement has a big role in the mechanical and retention properties of Hydrocarbon (HC). The particle size analysis revealed the presence of two particle size ranges for Portland cement. The grain size population varies between 3.90 and $451.55 \mu \mathrm{m}$ with a median size of $15.68 \mu \mathrm{m}$. The Fig 2.b shows the distribution histogram of the different particle size phases of the cement. The laser particle size measurement results for OPC were detailed in table 4.

\section{3 Solidification/Stabilization parameters improvement:}

\subsubsection{Effect of Cement}


In all experiments, sample 5 in Table 5 was chosen for the test because it has a higher oil level

(Oil \%=9.61). This crude sample is considered as a reference sample (RS). Table 5 depicts the hydrocarbons concentration with the different ratios of cement-to-drill cuttings $\left(C_{\text {cement }}\right)$. The ratios were $(0.02: 1),(0.04: 1),(0.06: 1),(0.09: 1),(0,11: 1)$ and $(0,13: 1)$. As it can be seen, the hydrocarbons concentration is inversely proportional to the concentration of $\mathrm{C}_{\text {cement }}$. The cement concentration was effective in reducing hydrocarbon concentration from the drill cuttings up to a (0.09:1). Increasing the cement concentration beyond (0.09:1) has no significant effect on the hydrocarbon reduction. Therefore, economically, the ratio of (0.09:1) cement-to-drill cuttings can be chosen as the optimal amount, to reduce the hydrocarbons concentration from the drilling cuttings obtained from Hassi Messaoud oil field. Increasing the cement concentration beyond (0.09:1) resulted, Theoretically, addition of cement results in formation of a more protected film hence forming a solid matrix which in turn strengthen the encapsulation process. Consequently, large hydrocarbons amounts are removed with addition of an optimized concentration of cement (Zhang and Bishop, 2002).

\subsubsection{Sand addition effect}

Table 5 illustrates the hydrocarbons percentage for different concentrations of sand. It is noticeable that the addition of sand reduces hydrocarbon ratio within the selected sample (RS). The hydrocarbon ratio reduced gradually from $9.61 \%$ to $5.21 \%$ after adding (0.04:1) of sand-to-drill cuttings. This was expected since adding sand to the mixture gives good cohesion, because the sand contributes to a good granular gradient, and from there, a balanced distribution of cement and additives inside the mixture (Belferra et al., 2016). The ratio (0.04:1) is considered as optimal concentration of sand for the reasons: after this amount of sand $(0.04: 1)$, the decrease in the hydrocarbon content is very low $(0.13 \%)$.

\subsubsection{Sodium silicate effect}

To determine the effect of sodium silicate concentration $\left(\mathrm{C}_{\mathrm{si}}\right)$ on hydrocarbons removal, different sodium silicate-drill cuttings ratios were tested. As it can be seen from Table 5 , the reduction of hydrocarbons percentage due to $\mathrm{C}_{\mathrm{si}}$ addition was significant until the ratio (0.006:1) of sodium silicate: drill cuttings. After this ratio, there is almost no change in hydrocarbons content. The Sodium silicate that was mixed with Portland cement improved mechanical properties such as the strength of materials (Wang et al., 2019).

\subsubsection{Activated carbon effect}

The effect of adding activated carbon on hydrocarbon concentration reduction is shown in Table 5. It is evidenced that the hydrocarbons content decreases until $5.88 \%$ after the ratio (0.013:1) of (activated carbon: drill cuttings). However, the hydrocarbons content starts to increase beyond this ratio of activated carbon: drill cuttings. This explains that the activated carbon considered like adsorbent of hydrocarbons (Arafat et al., 1999). The adsorption of hydrocarbon on activated carbon is much faster for until (0.013:1). It can be seen that the Table 5 contains an optimum concentration of activated carbon that should not be exceeded to avoid the release of hydrocarbons.

\subsubsection{Organophilic clay effect}

Table 5 shows the effect of adding organophilic clay for hydrocarbons removal. A gradual degradation of hydrocarbons is noticed with increasing the ratio of (organophilic clay : drill cuttings) until it reaches (0.013:1) which corresponds to a hydrocarbon content reduction of $6.25 \%$. After this ratio, the rate of hydrocarbons starts to increases again. Therefore, this ratio value is considered as the optimal value of organophilic clay and should not be exceeded so as not to have the opposite effect for this specific type of drill cuttings. This phenomenon is justified by two reasons; firstly, the clay is fragile, and this property affects the solidification of the treated samples matrix, when a certain concentration is exceeded, the contaminants will be released. Secondly, (0.013:1) of clay decreases the percentage of hydrocarbons to $6.25 \%$, which promotes the dispersion of the non adsorbed oily particles in the treated samples. the importance of the adsorbent of organophilic clay, either as a pre-treatment or as an additive, actually promotes the immobilization of the contaminants in the solidified-stabilized waste (Paria and Yuet, 2006).

\subsection{Combination of Optimum ratios}

In the previous section, the optimum parameters of solidification/stabilisation treatment were determined. The optimum concentrations results were for the cement-to-drill cuttings mass ratio is (0.09:1). For the additives-to-drill cuttings mass ratio are $(0.04: 1),(0.006: 1),(0.013: 1)$ and $(0.013: 1)$ for the sand, sodium silicate, Organophilic clay and activated carbon, respectively. At this stage, we aim to combine the last optimum results. Several mixtures where formulated in order to obtain the optimum formula. This involved the use of the obtained optimal concentrations of the tested parameters and the following mixtures were tested:

Cuttings + optimal of cement + optimal of sodium silicate $=$ Mixture $A$

Cuttings + optimal of cement + optimal activated carbon $=$ Mixture B

Then, the optimal quantity of the sand is added to the afore mentioned mixtures:

Cuttings + optimal of cement + optimal of sodium silicate + optimal of sand $=$ Mixture $C$

Cuttings + optimal of cement + optimal of activated carbon + optimal of sand $=$ Mixture D

Cuttings + optimal cement + optimal organophilic clay+ optimal sand = Mixture E 
Table 6 summarizes the results of these combinations on the hydrocarbon content within the studied sample. The mixture D with the activated carbon as adsorbent gave the best result, then that with the sodium silicate (mixture C) (Coz et al., 2009). These results are confirmed by other research results that have used the activated carbon as adsorbent for hazardous wastes treatment (Arafat et al., 1999) and in another for decomposition and remediation of hazardous organic materials(Zhang and Bishop, 2002)(Rho et al., 2001).

The results recorded in Table 6 showed that the sand improves the retention of hydrocarbons in both combinations. Because it strengthens the matrix formed by the cement which in turn gives the treated waste a better solidification. Moreover, the sand effect is more pronounced with sodium silicate (Mixture C) than that with activated carbon (Mixture D). For the same amount of sand, a decrease of $1.25 \%$ of hydrocarbons rate is obtained with the sodium silicate, whereas, only a decrease of $0.62 \%$ of hydrocarbons with the activated carbon is found. From the obtained results, sodium silicate (Mixture C), is selected to be treated with more stabilizers (optimal amounts) i.e., orgnophilic clay and activated carbon, as follows:

Cuttings + optimum of cement + optimum of sand + optimum of sodium silicate + optimum of orgnophilic clay $=$ Mixture $F$.

cuttings + optimum of cement + optimum of sand + optimum of sodium silicate + optimum of activated carbon $=$ Mixture G

Table 7 summarizes the results of these new combinations. From these results, the combination of an adsorbent with an encapsulant improves the results obtained in the samples stabilized by adsorption. Nevertheless, this decrease is not very important compared with the results obtained in the samples without combinations of stabilizers.

\subsection{Centrifugation Effect and Acceptance Test For Landfilling}

The optimised results using (Mixture G, 5.102\%) still insufficient for the landfilling, since they possess values that are above the tolerated value which is $5 \%$ (Abbas, 2011). Thus, for the solidification/stabilization process for drill cuttings highly contaminated by hydrocarbons, to be effective, the cuttings must be subjected to the pre-treatment (centrifugation, dilution) operation to confirm the regulations set by SONATRACH(Khodja, 2008),(Abbas, 2011). The results of the sample before (Mixture $\mathrm{G}$ ) and after centrifugation operation (Mixture ) are presented in Table 8 . From this table, it is found that the hydrocarbon content of our centrifuged sample dropped from 5.102 to $1.999 \%$ which meets the standards set by SONATRACH (mass percentage of hydrocarbon less than or equal to $5 \%$ ) (Abbas, 2011).

So, it can be declared that the sample of mixture at this rate, $1.999 \%$ of hydrocarbon content, had successfully passed the acceptance test for landfilling (in what concern the amount of hydrocarbons).

\subsubsection{Matrix Permeability}

After the analysis, the permeability of the treated sample is $59.71 \mathrm{mD}$. The treatment by solidification/stabilization gives a good result, because the cement fills the void that exists between the particles (contaminated by hydrocarbon) of the sample before treatment and solidifies it. Therefore, it makes the fluid passage within the matrix difficult. The solidification/stabilization effectiveness was confirmed by Ogechi et al. (S et al., 2010).

\subsubsection{Matrix Solidification Test: Resistance to Free Compression (RFC)}

Fig 3.a shows the Compressive strength of the treated sample during curing time. It can be noticed that curing of the sample increases with time, as: $84.24,139.18,186.39,211.88$ and $246.04\left(\mathrm{~kg} / \mathrm{cm}^{2}\right)$ after $3,7,21,28$ and 96 days, respectively. The Strength test is used to provide a comparison between stabilized and unstabilized drill waste cuttings (Malviya and Chaudhary, 2006). Hence, it can be deduced that the proposed treatment criteria using the solidification/stabilisation method improves the mechanical properties of the drilling waste. The EPA (United States Environmental Protection Agency) Guide considered that $0.35 \mathrm{MPa}$ is the value to have a satisfactory compressive strength ("Guide to disposal of chemically stabilized and solidified wastes," 1982). This value ( $0.35 \mathrm{Mpa}$ ) has been proposed as a minimum value for materials to be landfilled. Accordingly, this confirms that our treated cuttings are very acceptable for landfilling. Compressive strength was tested at different time by Malviya and Chaudhary (Malviya and Chaudhary, 2004). They reported that compressive strength increases as the curing time increases (Malviya and Chaudhary, 2006). However, many other factors affect the effectiveness of solidification/stabilization such as cuttings nature and its proprieties, waste/cement ratio, type of cement, curing days etc (Malviya and Chaudhary, 2004)(Malviya and Chaudhary, 2006). .

\subsubsection{Stabilization Tests of the Treated Waste}

3.5.3.1. Atomic absorption spectrophotometry for the retention of heavy metals

Table 9 presents the results of Atomic Absorption Spectrophotometry Analysis (AAS) of the waste sample before and after treatment, compared to the maximum tolerated values for the landfilling. From the results recorded in Table 9 , it can be seen that the solidification/stabilization treatment is very effective for heavy metals elimination (S et al., 2010). Moreover, the results of the analysis of our sample after treatment pass the testing standards (below the maximum tolerated values) only traces of $\mathrm{Zn}$ remained. This confirms that our treated sample strongly passes the leaching test.

\subsection{Acceptance Test of the Treated Waste for Recovery}

Fig.3.b represents the variation of the resistance to free compression as a function of the cement concentration after 7 curing days. According to Fig. 3.b, the resistance to free compression (RFC) of our treated sample increases with increasing cement content which surpasses the allowed minimum value (0.35 MPa), ("Guide to disposal of chemically stabilized and solidified wastes," 1982), by many times. It is deduced from this test that the pre-treated 
sample was very brittle, so, the production of concrete from the treated waste requires the addition of considerable quantities of cement. The cement offers a sturdy structure to the treated sample and bind well the harmful heavy metals which prevents their movement in a monolithic mass (Masrullita et al., 2018).

\subsection{Shape and Morphology of the Treated Drill Cuttings}

To discuss the effects of the solidification/stabilization process on the treated drill cuttings, it is important to investigate the surface morphology before landfilling. Figs. 4 a,b, and c show the images of the treated drill cuttings at different times after mixing: 7, 28, and 96 days respectively, obtained using the SEM technic. The SEM structure indicates that the samples consist of granules of clay materials, with silicon as the predominant component. They also show high carbon ( $\mathrm{HC}$ ), calcium hydroxide, $\mathrm{C}-\mathrm{SH}$, and some aggregates of grain-like. Therefore, it can be concluded that the time after mixing has no effect on the sample morphology but rather had an effect on hardness and durability of the sample. Furthermore, the shapes and surfaces of the three obtained samples, indicate that the sample $\mathrm{C}$ is more solid and stable compared to the other samples. This later result was confirmed by the results of compressive strength which is proportional to the curing time because the porosity has an impact on the strength (Wang et al., 2019). The tests have also revealed that the final stabilized outcome of Portland cement is a concrete of low permeability sturdy compact matrix related to liquid substances (hydrocarbons) (Clark and Perry, 1985;Poon et al.,1985; Zhao et al.,1999; Lake and Menzies, 2007), which offer an appropriate pore arrangement for storing the substances within it (Young,1992). These facts clarify the reason of the very low amounts of heavy metals for the sample after S/S treatment found in Table 9.

\section{Conclusion}

The stabilization/solidification (S/S) process can be used to treat the majority of industrial wastes. Overall, the final wastes which cannot undergo an energy or material recovery can be treated by the S/S process. The effectiveness of the treatment depends mainly on the mechanical properties of the cement and particularly its resistance to compression. Environmental protection is paramount in the whole world. These polluting discharges must undergo a stabilization/solidification treatment to avoid any contamination of the soil and subsoil. To overcome this problem, the national and international laws concerning the environment and the treatment of discharges (solid and liquid) must be strictly applied and respected.

In this study, the inerting of Algerian petroleum drill cuttings waste extracted from Hassi Messaoud oil field and the immobilisation of heavy metals and hydrocarbons contained within it is optimized using S/S treatment. This is achieved by revealing the optimum concentration of the five most commonly used elements in the S/S treatment (cement as hydraulic binder, sand, sodium silicate, Organophilic clay and activated carbon as additives). In the second stage, these optimum concentrations of each element are mixed with a special manner to uncover the optimum formula that gives the best results for the disposal of this type of organic wastes.

Based on the results obtained from this study, the S/S treatment by the addition of cement and sodium silicate has been proven to be very effective. The optimum concentrations were found to be (0.09:1), (0.04:1), (0.006:1), (0.013:1) and (0.013:1) for the cement, sand, sodium silicate, Organophilic clay and activated carbon, respectively. The combination of these optimums was evaluated to obtain an excellent result of the treated drill cuttings for landfilling. The obtained results show that the hydrocarbon content of our sample, dropped from 9.40 to $1.999 \%$ which fits very well the safety standards. Besides that, the treated drilling waste have successfully passed the leaching and mechanical tests after its subjecting to several severe tests and treatments where only some traces of $\mathrm{Zn}$ were found after treatment (0.13). The analysis and the results of our samples before and after the S/S treatment are evaluated and ensured by advanced means and methods such as: SEM, AASA, RFC, centrifugation .... From the light of the obtained results it can be declared that the treated waste can be recovered and reutilized in some construction application such as road construction and pavement.

\section{Declarations}

\section{ACKNOWLEDGEMENTS}

The authors are grateful to the SONATRACH National Oil Company in Algeria. Also, the Department of oil drilling in Kasdi Merbah University, and Department of Chemical and Petroleum Engineering at the University of Calgary is greatly appreciated. A special acknowledgement to Mr. Aiad Lahcen for his help.

\section{References}

1. Abbas, A.H., 2011. Les bourbiers de forages pétroliers et des unités de production:Impact sur l'environnement et technique de traitement. Kasdi Merbeh Ouargla.

2. Arafat, H.A., Hebatpuria, V.M., Rho, H.S., Pinto, N.G., Bishop, P.L., Buchanan, R.C., 1999. Immobilization of phenol in cement-based solidified/stabilized hazardous wastes using regenerated activated carbon: Role of carbon. J. Hazard. Mater. 70, 139-156. https://doi.org/10.1016/S03043894(99)00127-2

3. Belferra, A., Kriker, A., Abboudi, S., Bi, S.T., 2016. Effect of granulometric correction of dune sand and pneumatic waste metal fibers on shrinkage of concrete in arid climates. J. Clean. Prod. 112, 3048-3056. https://doi.org/10.1016/j.jclepro.2015.11.007

4. Boutammine, H., Salem, Z., Khodja, M., 2020. Petroleum drill cuttings treatment using stabilization/solidification and biological process combination. Soil Sediment Contam. 29, 369-383. https://doi.org/10.1080/15320383.2020.1722982 
5. Clark Al, Perry R Cement-Based Stabilization/Solidification Processes for the disposal of toxic wastes. Proceedings from a Workshop on Environmental Technology Assessment. Beaurmont, PWR, Jain, RK and Engelbrecht, RS, Eds. pp. 1 - 44.(1985)., n.d.

6. Coz, A., Andrés, A., Soriano, S., Viguri, J.R., Ruiz, M.C., Irabien, J.A., 2009. Influence of commercial and residual sorbents and silicates as additives on the stabilisation/solidification of organic and inorganic industrial waste. J. Hazard. Mater. 164, 755-761.

https://doi.org/10.1016/j.jhazmat.2008.08.079

7. Guide to disposal of chemically stabilized and solidified wastes, 1982. . U.S EPA SW872. https://doi.org/10.1016/0016-2361(79)90171-6

8. Kherfi.A, Ganoune.L, Etude de I' efficacité des méthodes de traitement de boue de forage appliquée. Memoire de licence, Universite Kasdi Merbeh Ouargla,2018, n.d.

9. Khodja, M., 2008. Les Fluides De Forage: Etude Des Performances Et Considerations Environnementa 198.

10. Krauthammer, T., Elfahal, M.M., Lim, J., Ohno, T., Beppu, M., Markeset, G., 2003. Size effect for high-strength concrete cylinders subjected to axial impact. Int. J. Impact Eng. 28, 1001-1016. https://doi.org/10.1016/S0734-743X(02)00166-5

11. Lake, C.B., Menzies, T., 2007. Assessment of two thermally treated drill mud wastes for landfill containment applications $394-401$. https://doi.org/10.1177/0734242X07073652

12. Larbi, A., Daaou, M., Faraoun, A., 2015. Investigation of structural parameters and self-aggregation of Algerian asphaltenes in organic solvents. Pet. Sci. 12, 509-517. https://doi.org/10.1007/s12182-015-0041-x

13. Laroche, O., Wood, S.A., Tremblay, L.A., Ellis, J.I., Pawlowski, J., Lear, G., Atalah, J., Pochon, X., 2016. First evaluation of foraminiferal metabarcoding for monitoring environmental impact from an offshore oil drilling site. Mar. Environ. Res. 120, 225-235.

https://doi.org/10.1016/j.marenvres.2016.08.009

14. Leonard, S.A., Roy, A.D., Stegemann, J.A., 2010. Stabilization/solidification of petroleum drill cuttings: Thermal and microstructural studies of binder hydration products. Environ. Eng. Sci. 27, 889-903. https://doi.org/10.1089/ees.2010.0147

15. Leonard, S.A., Stegemann, J.A., 2010. Stabilization/solidification of petroleum drill cuttings: Leaching studies. J. Hazard. Mater. 174, $484-491$. https://doi.org/10.1016/j.jhazmat.2009.09.078

16. Liu, J., Nie, X., Zeng, X., Su, Z., 2012. Cement-based solidification/stabilization of contaminated soils by nitrobenzene. Front. Environ. Sci. Eng. China 6, 437-443. https://doi.org/10.1007/s11783-012-0406-y

17. Malviya, R., Chaudhary, R., 2006. Factors affecting hazardous waste solidification/stabilization: A review. J. Hazard. Mater. 137, $267-276$. https://doi.org/10.1016/j.jhazmat.2006.01.065

18. Malviya, R., Chaudhary, R., 2004. Study of the treatment effectiveness of a solidification/stabilization process for waste bearing heavy metals. J. Mater. Cycles Waste Manag. 6, 147-152. https://doi.org/10.1007/s10163-004-0113-2

19. Masrullita, Perry Burhan, R.Y., Trihadiningrum, dan Y., 2018. Stabilization/solidification of waste containing heavy metals and hydrocarbons using OPC and land trass cement. J. Ecol. Eng. 19, 88-96. https://doi.org/10.12911/22998993/92926

20. Montgomery, D.M., Sollars, C.J., Perry, R., Tarling, S.E., Barnes, P., Henderson, E., 1991. Treatment of Organic-Contaminated Industrial Wastes Using Cement-Based Stabilization/Solidification- li. Microstructural Analysis of the Organophilic Clay as a Pre-Solidification Adsorbent. Waste Manag. Res. 9, 113-125. https://doi.org/10.1177/0734242X9100900116

21. Paria, S., Yuet, P.K., 2006. Solidification-stabilization of organic and inorganic contaminants using portland cement: A literature review. Environ. Rev. 14, 217-255. https://doi.org/10.1139/A06-004

22. Poon CS, Peters CJ, Perry R Mechanisms of Metal Stabilization by Cement Based Fixation Processes. Sci. Total Environ. Elsevier Holland pp. 55 - 71. (1985), n.d.

23. Rho, H., Arafat, H.A., Kountz, B., Buchanan, R.C., Pinto, N.G., Bishop, P.L., 2001. Decomposition of hazardous organic materials in the solidification/stabilization process using catalytic-activated carbon. Waste Manag. 21, 343-356. https://doi.org/10.1016/S0956-053X(00)00080-5

24. Rosener, M., 2008. Etude pétrophysique et modélisation des effets des transferts thermiques entre roche et fluide dans le contexte géothermique de Soultz-sous-Forêts. To cite this version: HAL Id: tel-00202959 Etude pétrophysique et modélisation des effets des transferts.

25. S, E.O.O., Ibifuro, A.M., Elijah, T.I., 2010. Stabilization/solidification of synthetic Nigerian drill cuttings. African J. Environ. Sci. Technol. 4, $149-153$. https://doi.org/10.5897/ajest09.012

26. Tanikawa, W., Shimamoto, T., 2006. Klinkenberg effect for gas permeability and its comparison to water permeability for porous sedimentary rocks. Hydrol. Earth Syst. Sci. Discuss. 3, 1315-1338. https://doi.org/10.5194/hessd-3-1315-2006

27. Vaccari, M., Castro, F.D., 2019. Non-conventional stabilisation/solidification treatment of industrial wastes with residual powdered paints. Waste Manag. Res. 37, 1012-1024. https://doi.org/10.1177/0734242X19860178

28. Vehlow, J., 2012. Reduction of dioxin emissions from thermal waste treatment plants: A brief survey. Rev. Environ. Sci. Biotechnol. 11, $393-405$. https://doi.org/10.1007/s11157-012-9296-5

29. Wang, Z., Sun, Y., Zhang, S., Wang, Y., 2019. Effect of sodium silicate on Portland cement/calcium aluminate cement/gypsum rich-water system: Strength and microstructure. RSC Adv. 9, 9993-10003. https://doi.org/10.1039/c8ra09901d

30. Yoon, S., Bhatt, S.D., Lee, W., Lee, H.Y., Jeong, S.Y., Baeg, J.O., Lee, C.W., 2009. Separation and characterization of bitumen from Athabasca oil sand. Korean J. Chem. Eng. 26, 64-71. https://doi.org/10.1007/s11814-009-0011-3 
31. Young JF, Dense High Strength, Low Permeability Cement Based Materials for Containment. Proc. 1st Intl Symposium, Cement Industry Sol. to Waste Mgt, Canadian Portland Cement Assoc. Toronto pp. 13-22. (1992), n.d.

32. Zhang, J., Bishop, P.L., 2002. Stabilization/solidification (S/S) of mercury-containing wastes using reactivated carbon and Portland cement. J. Hazard. Mater. 92, 199-212. https://doi.org/10.1016/S0304-3894(02)00019-5

33. Zhao T, Zhu J, Chi P ,Modification of Pore Chemicals in evaluation of High-Performance Concrete Permeability. ACI Mater. J. $96: 84$ - 89. (1999), n.d.

\section{Tables}

\section{Table 1}

Characteristics of solid sand.

\begin{tabular}{|ll|}
\hline Parameters & Cube test sand \\
\hline Specific gravity & 2.65 \\
\hline Bulk density & $93.45 \mathrm{lb} / \mathrm{ft}^{3}\left(1.497 \mathrm{~g} / \mathrm{cm}^{3}\right)$ \\
\hline
\end{tabular}

\section{Table 2}

Hydrocarbons and heavy metals contents of the studied crude drill cuttings compared to the maximum conventionally tolerated values.

\begin{tabular}{|c|c|c|c|c|c|c|c|c|}
\hline & & \multicolumn{6}{|c|}{ Heavy metals concentration (mg/l) } & \multirow[t]{2}{*}{ Content of hydrocarbons (\%) } \\
\hline & & $\begin{array}{l}\text { Lead } \\
(\mathrm{pb})\end{array}$ & $\begin{array}{l}\text { copper } \\
\text { (Cu) }\end{array}$ & $\begin{array}{l}\text { chromium } \\
\text { (Cr) }\end{array}$ & $\begin{array}{l}\text { Cadmium } \\
\text { (Cd) }\end{array}$ & $\begin{array}{l}\text { Zinc } \\
\text { (Zn) }\end{array}$ & $\begin{array}{l}\text { manganese } \\
(\mathrm{Mn})\end{array}$ & \\
\hline \multicolumn{2}{|c|}{ Maximum tolerated values } & 1 & 3 & 3.1 & 0.2 & 5 & 1 & $<5 \%$ \\
\hline \multirow[t]{6}{*}{ Samples } & 1 & 32.6 & 00 & 00 & 0.1 & 8.5 & 1.8 & 4.40 \\
\hline & 2 & 46.5 & 00 & 0.7 & 0.1 & 12.6 & 2.1 & 4.00 \\
\hline & 3 & 15.8 & 1.6 & 00 & 00 & 7.4 & 1.7 & 4.65 \\
\hline & 5 & 7.2 & 00 & 00 & 0.1 & 0.78 & 1.9 & 9.61 \\
\hline & 6 & 8.04 & 00 & 00 & 0.1 & 6.7 & 1.8 & 6.56 \\
\hline & 7 & 14.1 & 00 & 00 & 0.2 & 5.3 & 1.2 & 9.40 \\
\hline
\end{tabular}

\section{Table 3}

Elementary chemical composition of OPC expressed in percentage by mass (\%)

\begin{tabular}{|c|c|c|c|c|c|c|c|c|c|c|c|c|c|c|c|c|}
\hline Che & ical elements & & & & & & & & & & & & & & & \\
\hline $\mathrm{N}^{\circ}$ & Designation & $\mathrm{SiO}_{2}$ & $\mathrm{Al}_{2} \mathrm{O}_{3}$ & $\mathrm{Fe}_{2} \mathrm{O}_{3}$ & $\mathrm{CaO}$ & $\mathrm{MgO}$ & $\mathrm{Mn}_{2} \mathrm{O}_{3}$ & $\mathrm{Na}_{2} \mathrm{O}$ & $\mathrm{K}_{2} \mathrm{O}$ & $\mathrm{P}_{2} \mathrm{O}_{5}$ & $\mathrm{TiO}_{2}$ & $\mathrm{SO}_{3}$ & Sro & $\mathrm{Cr} 2 \mathrm{O} 3$ & Zno & TOT \\
\hline 1 & Sample 03 & 21.19 & 4.58 & 6.13 & 64.33 & 1.28 & 0.03 & 0.14 & 0.34 & 0.19 & 0.19 & 1.83 & 0.30 & 0.009 & 0.047 & 100.59 \\
\hline
\end{tabular}

\section{Table 4}

Laser particle size measurement results for OPC 


\begin{tabular}{|c|c|c|c|c|}
\hline Number & Diameter (Microns) & Passing & $q(\%)$ & Cumulative Passing (\%) \\
\hline 74 & 229.075 & 0.432 & & 95.999 \\
\hline 75 & 262.376 & 0.71 & & 96.708 \\
\hline 76 & 300.518 & 1.032 & & 97.74 \\
\hline 77 & 344.206 & 1.212 & & 98.952 \\
\hline 78 & 394.244 & 0.674 & & 99.626 \\
\hline 79 & 451.556 & 0.374 & & 100 \\
\hline 80 & 517.2 & 0 & & 100 \\
\hline
\end{tabular}

\section{Table 5}

The hydrocarbons concentration with the different ratios of parameters-to-drill cuttings.

\begin{tabular}{|c|c|c|c|c|c|c|c|c|c|c|c|}
\hline \multirow[t]{2}{*}{ Parameters } & \multicolumn{11}{|c|}{ Concentrations } \\
\hline & (RS) & $0.02: 1$ & $0.04: 1$ & $0.06: 1$ & $0.09: 1$ & $0.11: 1$ & $0.13: 1$ & & & & \\
\hline Cement concentration & & & & & & & & / & / & / & / \\
\hline \multirow[t]{3}{*}{ Hydrocarbon content (\% ) } & 9.61 & 7.02 & 6,84 & 6.75 & 6.56 & 6.54 & 6.52 & & & & \\
\hline & & & & & & & & / & / & l & / \\
\hline & (RS) & 0.009 & 0.018 & 0.02 & 0.03 & 0.04 & 0.05 & 0.06 & 0.07 & 0.08 & 0.09 \\
\hline Sand & & $: 1$ & $: 1$ & $: 1$ & $: 1$ & $: 1$ & $: 1$ & $: 1$ & $: 1$ & $: 1$ & $: 1$ \\
\hline \multicolumn{12}{|l|}{ Concentration } \\
\hline \multirow[t]{2}{*}{ Hydrocarbon content (\% ) } & 9.61 & 6.11 & 5.81 & 5.49 & 5.44 & 5.21 & 5.19 & 5.14 & 5.12 & 5.11 & 5.08 \\
\hline & (RS) & $0.003: 1$ & $0.006: 1$ & 0.009:1 & $0.012: 1$ & $0.015: 1$ & & & & & \\
\hline Sodium silicate & & & & & & & / & / & / & / & / \\
\hline \multicolumn{12}{|l|}{ Concentration } \\
\hline \multirow[t]{2}{*}{ Hydrocarbon content (\% ) } & 9.61 & 7.8 & 6.56 & 6.54 & 6.52 & 6.51 & / & / & / & / & / \\
\hline & (RS) & $0.004: 1$ & 0.009:1 & 0.013:1 & 0.018:1 & 0.022:1 & $0.027: 1$ & / & / & l & / \\
\hline \multicolumn{12}{|l|}{ Activated carbon Concentration } \\
\hline \multirow[t]{2}{*}{ Hydrocarbon content (\% ) } & 9.61 & 6.9 & 6.25 & 5.88 & 6.48 & 6.23 & 6.75 & / & / & / & / \\
\hline & (RS) & 0.004:1 & 0.009:1 & 0.013:1 & 0.018:1 & 0.022:1 & $0.027: 1$ & & & & \\
\hline Organophilic clay concentration & & & & & & & & / & / & / & / \\
\hline Hydrocarbon content (\% ) & 9.61 & 7.49 & 6.75 & 6.25 & 6.48 & 6.85 & 7.00 & / & / & I & / \\
\hline
\end{tabular}

\section{Table 6}

Combinations results of optimums of stabilizers with optimums of sand and cement.

$\begin{array}{lllllll}\text { Samples compositions } & \text { (RS) } & \text { Mixture A } & \text { Mixture B } & \text { Mixture C } & \text { Mixture D } & \text { Mixture E } \\ \text { Hydrocarbon content (\%) } & 9,61 & 6,482 & 5,811 & 5,227 & 5,191 & 6.250\end{array}$


Combinations results of the optimums of adsorbent with the optimum

of sodium silicate, cement and sand.

\begin{tabular}{|llll|}
\hline & & \multicolumn{2}{l|}{ Samples with combinations of Stabilizers } \\
\hline Samples compositions & (RS) & Mixture F & Mixture G \\
\hline Hydrocarbon content (\%) & 9.61 & 5.124 & 5.102 \\
\hline
\end{tabular}

\section{Table 8}

Results before and after centrifugation of the optimal mixture.

\begin{tabular}{lll} 
Sample & $\begin{array}{c}\text { before centrifugation } \\
\text { "Mixture G" }\end{array}$ & $\begin{array}{c}\text { after centrifugation } \\
\text { "Mixture " }\end{array}$ \\
\hline Hydrocarbon content (\%) & 5.102 & 1.999
\end{tabular}

\section{Table 9}

Results of atomic absorption spectrophotometry.

\begin{tabular}{lllllll} 
Heavy Metals & $\mathrm{Cd}$ & $\mathrm{Cr}$ & $\mathrm{Pb}$ & $\mathrm{Mn}$ & $\mathrm{Cu}$ & $\mathrm{Zn}$ \\
\hline maximum tolerated values (mg/l) (Abbas, 2011) & 0.2 & 3.1 & 1 & 1 & 3 & 5 \\
\hline Before treatment $(\mathrm{mg} / \mathrm{l})$ & 0.1 & 0 & 7.2 & 1.9 & 0 & 0.78 \\
\hline After treatment $(\mathrm{mg} / \mathrm{l})$ & 0 & 0 & 0 & 0 & 0 & 0.13
\end{tabular}

\section{Figures}

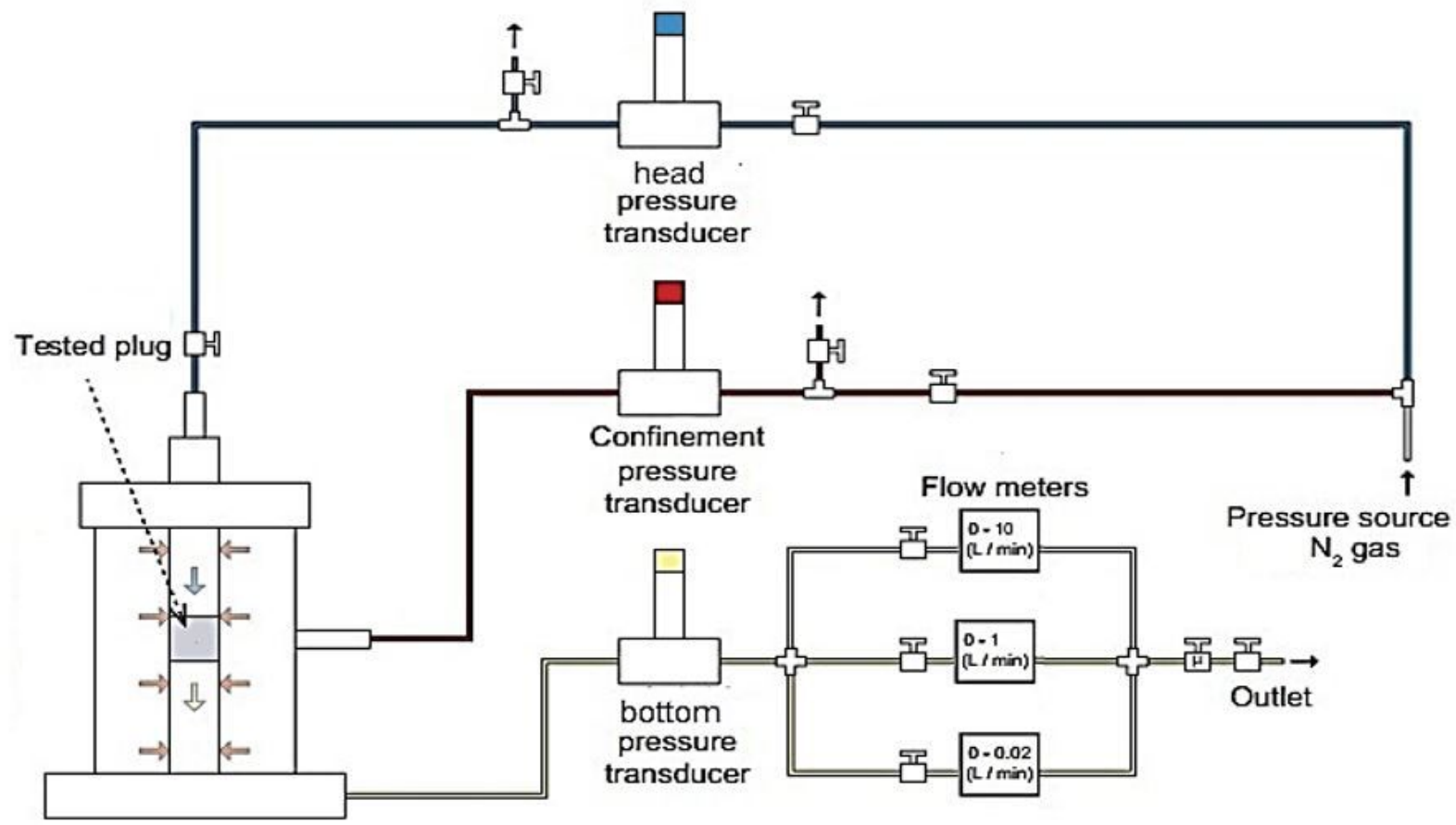

Figure 1

A diagram showing the Permeameter device using nitrogen gas flow. 
Consts
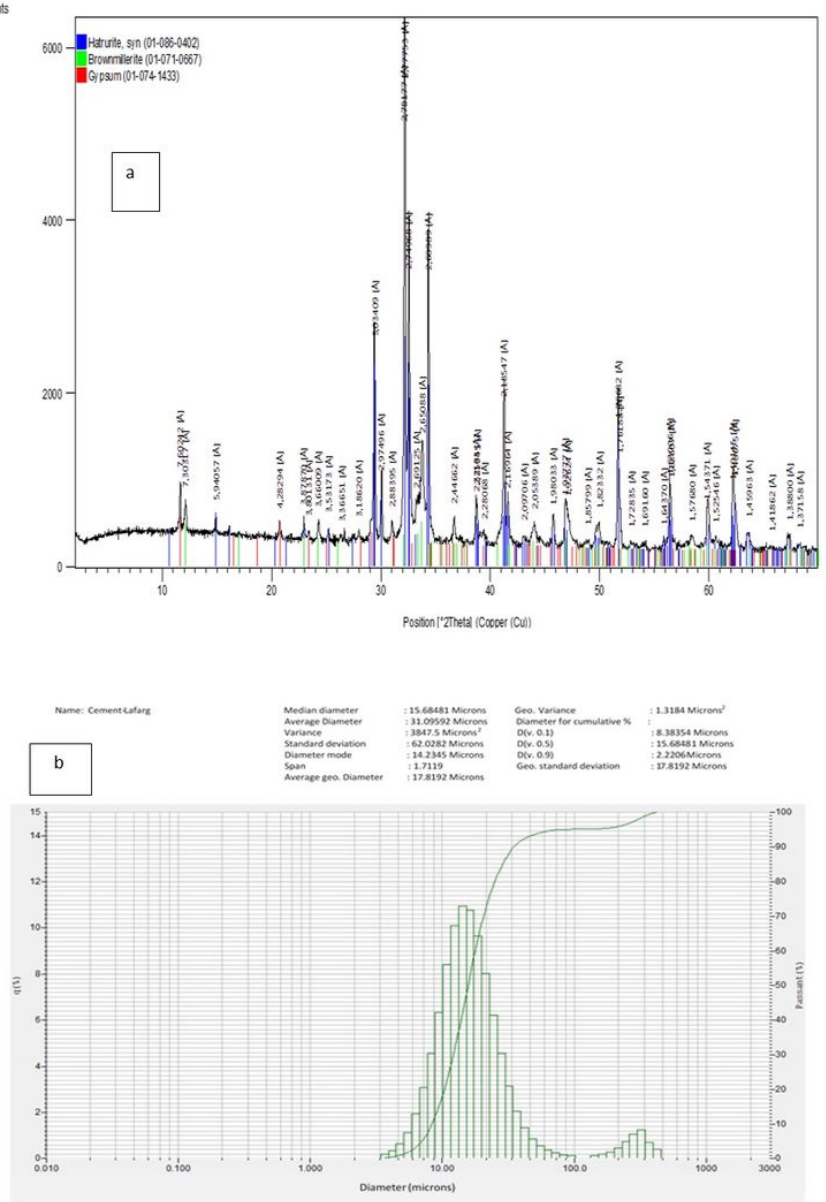

Figure 2

a. diffractogram of the cement sample, b. distribution Histogram of the different particle size phases of the cement.
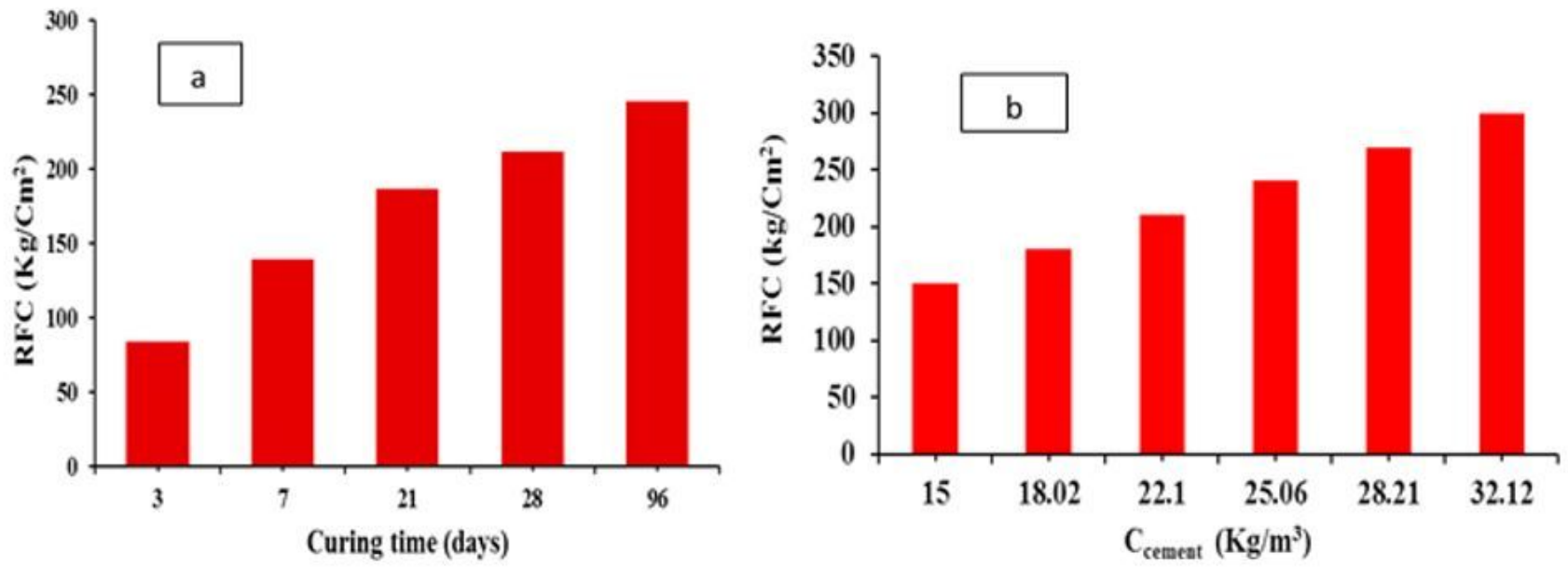

Figure 3

a. Resistance to free compression vs curing days. b. Variation in mechanical strength as a function of the concentration of cement. 

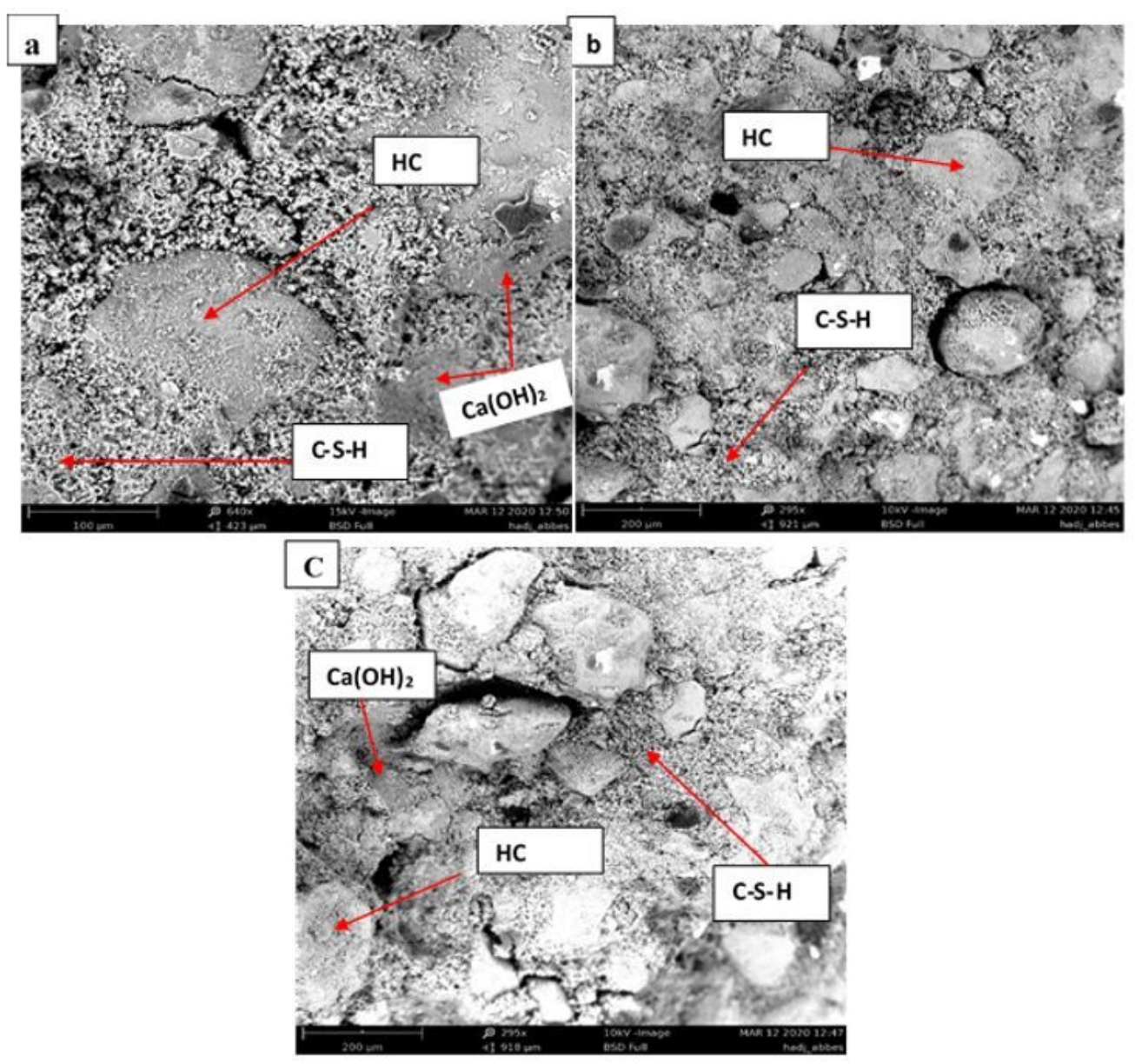

Figure 4

SEM images for treated drill cuttings. (a) 7days after mixing (b) 28 days after mixing (C) 96 days after mixing. 